\title{
Ethnographic Field Notes and Reflexivity
}

\author{
Päivi Eriksson ${ }^{1}$, Elina Henttonen ${ }^{2}$ and Susan Meriläinen ${ }^{3}$ \\ 1 University of Eastern Finland \\ ${ }^{2}$ Aalto University School of Economics \\ 3 University of Lapland \\ Finland
}

\section{Introduction}

Ethnographers have devoted a great deal of attention on the issues of writing the final product of ethnographic research, the ethnographic research report. The issues related to the process of writing ethnographic field notes, however, have received much less attention in methodological discussions. Emerson et al. (1995) point out that even after the discovery of 'writing' as a central practice of ethnographic research (Clifford \& Marcus 1986, Van Maanen 1988), field notes remained as 'invisible work' in ethnographic literature. They argue that while many ethnographers are uneasy with the messy, unfinished, and personal character of their field notes, these have mostly remained private documents. Remaining private documents, the impact of field notes on research findings and results has also left unexplored.

Why should we pay more attention to field notes? Although there is no consensus concerning how ethnographic field notes should be written and what is their value in ethnographic research, most ethnographers (and many other qualitative researchers) produce some kind of field notes, particularly when doing observations. When planning and producing field notes in situ or after wards ethnographers continuously make choices about what to write down and how. Because it is impossible to collect data on everything and record all the things that are going on in the field, the researcher needs, by necessity, be selective in her writing. Furthermore, the researcher writes down her notes drawing from her sense making of the people, events and the situation and her interpretation can be different, or at least have different details and nuances, compared to another researchers' field notes from the same situation. Field notes are important because they involve the critical acts of sense making and interpretation, which inevitably have some kind of bearing on the research findings and results. To be able to understand what kind of bearing the field notes can have on your research, it is necessary to practice reflexivity in respect to one's own field notes and their analysis.

In this chapter, we will answer to the request of taking written field notes and their analysis more seriously in ethnographic research. Our main objective is to open up and analyse the process of writing and analysing ethnographic field notes. We will perform this through the investigation of our joint research project, which focused on business, technology and gender in the context of the Finnish ICT-sector (for an overview of the project, see 
Henttonen 2010). In our investigation, we will practice reflexivity in terms of exploring the relationship between the researcher and the field, questioning the knowledge that is produced in field notes and in their analysis. More specifically, we will focus attention on how the social identities of the researchers affect how knowledge about the research subjects is produced and with kind of consequences.

Our analysis elaborates two different modes of writing the field notes - selection and sensemaking activities and textual practices of representation - and their implications on our research. In our analysis, we will pay close attention to the processes of exclusion, which take place through othering and marginalizing certain groups of actors involved in our research. With regards to selection and sense-making activities, we will ask what and who do we decide as 'important' and 'relevant' enough to be included into our field notes. We will also investigate why we considered some actors and events to be 'not-so-relevant' in relation to the goals of our project and how we justified these choices in our field notes. Through the analysis of our textual practices, we will further illustrate how and with what kinds of implications the 'relevant' and 'not-so-relevant' actors and encounters were crafted in our notes.

\section{Collective reflexivity and social identity}

In general, reflexivity can be understood as an essential human capacity to make sense of our social existence, i.e. something that we are all engaged with on everyday basis. In scholarly contexts, it is useful to make a distinction between the concepts of 'reflection' and 'reflexivity'. 'Reflection' refers to a methodological principle whereby the researcher aims to make sure that her own experiences, biases and interpretations do not influence the analysis, findings and conclusions. Therefore, the concept of reflection is often connected to objectivity in research (Etherington 2006, 28). In this sense, reflection is part of the more traditional ethnographic research, which has been called 'naturalistic' and 'positivistic' ethnography.

A general goal of the main stream ethnographic research is to describe a culture or subculture in as much detail as possible, including language, customs, and values (Eriksson \& Kovalainen 2008). This typically involves becoming a participant observer and socialising oneself into the culture under study. The actual process of ethnography means that the researcher is immersed in a social setting for a certain period of time, in which they make regular observations of the behaviour of the group under study. Just as any other researchers, however, ethnographers inevitably put their own slant into the research because they are the ones making the decisions on what to observe and what to note down. Furthermore, even though the ethnographer uses several methods of recording their findings, it is highly unlikely that they capture all of the relevant aspects of the social processes, as there is simply too much going on at one time to focus on everything. Therefore, text books advice researchers to take stock of the information she has collected. In this context, reflection entails that the ethnographer writes about the potential biases or influences, so that the reader can be aware of them when reading and interpreting the data.

Along with the emergence of postmodernism and the linguistic turn in social science research, and the development of various constructionist research approaches (Alvesson \& Söldberg 2000), there has emerged an increasing interest in 'new' or 'postmodern' reflexivity 
(Etherington 2006, Lynch 2000). In this context, reflexivity refers broadly to the relationship between the researcher and the empirical field, questioning the notions of the realities we study, ways we generate knowledge, and ways we theorize (Cunliffe 2003). The basic argument in the recent discussions of reflexivity is that the authors should explicitly position themselves in relation to the research objects of the study to enable the audience to assess their knowledge claims in terms of the situated aspects of their social selves, values and assumptions (Maton 2003, 54). This development has led to different forms and uses of reflexivity (Davies 2008; Etherington 2006, Pillow 2003), to the extent that Lynch (2000) writes about 'reflexivities'.

One way to classify the forms of reflexivity is to make a distinction between 'individualistic' and 'collective' reflexivities. Individualistic reflexivity is typically used to produce confessional tales from the field (Van Maanen 1988) whereas collective reflexivity analyses how research communities and members within these communities produce collective meaning (Hardy et al. 2001, Maton 2003). Individualistic reflexivity has faced some critique according to which there is a thin line between epistemologically productive reflection, e.g. finding a suitable way to acknowledge one's position in one's texts (Rhodes 2000), and the forms of reflexivity that have been called as self-indulgence, navel-gazing, or warped narcissism (Coffey 1999).

Social identity theory (see e.g. Ellemers et al. 1999, Haslam 2001) provides a useful framework for elaborating on collective reflexivity, which revolves around the question of how shared collective understandings affect the world views and interpretations of people. While being different from personal identity, which is based on personal characteristics and individual relationships, social identity theory deals with the social nature of self as constituted by society' (Hogg et al. 1995, 255). In this way, social identity is a concept that connects individuals and society. The basic idea of the social identity theory is based on the issue that all of us belong to different types of groups (e.g. business school researchers, ethnographers, female entrepreneurs) and derive at least part of our identities from these groups. Identity formation in relation to groups takes place in three stages: social categorization, social identification and comparison. When developing the social identity of the group, the members construct an in-group (we) and various out-groups (others) and go through a mixture of inclusion and exclusion processes, which can have both negative and positive consequences (Haslam 2001). While social identity theory is sensitive to the contextual dimension of identity formation, it provides an understanding of identities as multiple and changing and residing in circumscribed practices such as norms and roles (Hogg et al. 1995, 255).

Common processes with negative consequences for the members of the out-groups are 'othering' and 'marginalization' (Barter-Godfrey \& Taket 2009). In the process of othering, an out-group is constructed as strange, un-familiar and different in contrast to the in-group,

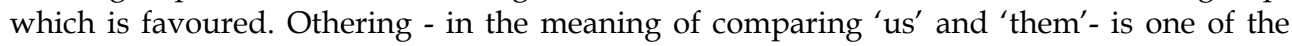
main mechanisms of collective identity construction. Therefore, collective reflexivity almost inevitably includes some type of analysis of it. Another, perhaps more extreme way of excluding the out-group is 'marginalization', which refers to a social process in which an out-group is assigned a position in the fringe of the society, or some other relevant entity (e.g. economy, business world). The processes of inclusion and exclusion are not necessarily goal-oriented or conscious and they are also pursued by people who are not even sure about 
their full membership within the in-group. These processes typically take place in strange or surprising situations when our self-esteem, or subjective uncertainty, is low. As we know, field work is often invaded by these types of situations, and this was the case in our field work also.

Carl Rhodes $(2000,522)$ suggests that researchers can acknowledge their position in their texts and account for their social roles in (re)presenting others while still not succumbing to excessive description about themselves as individuals. In this way they can take responsibility for their own textual practices through which they construct the world and lives of others. This is what we aim at in this chapter. We acknowledge our social identities as business school researchers and members of respective cultural and scientific communities. At the same time, however, we wish to move away from 'navel-gazing' into showing how collective cultural understandings which are alive in our research communities but also the sense making processes of our own small research group shape our research practice.

\section{The process of our field work}

The three of us (co-authors) have received their master's degrees and doctorates from Finnish business schools and have since then worked within the same context. The starting point for the fieldwork illustrated in this paper was our joint research project that examined women owner-managers of small Finnish ICT-companies - a project conducted within a national research programme for technology and innovation policy. Within the research programme, the goal of our project was to produce information on women's business activities in the Finnish ICT-sector, analyse how these companies were managed, and examine how women's business initiatives in technology-intensive industries were (or could be) supported. In our research project, we first collected policy texts and media texts on women-controlled companies in these types of businesses. Thereafter, we made interviews with the female CEOs of 17 small technology intensive companies, mostly within the ICTsector (for an overview, see Henttonen 2010). Thereafter, we negotiated access to four small software service companies for the purpose of doing ethnographic fieldwork with four women owner-managers (for details, see Eriksson et al. 2005, 2008a, 2008b). Before we started the ethnographic field work, we studied a number of ethnographic text books as carefully as we could.

The methodological literature (e.g. Atkinson et al. 2001, Coffey 1999, Emerson et al. 1995, Eriksson \& Kovalainen 2008) provides plenty of guidelines concerning how to collect and report observational data for ethnographic research. First of all, the literature advices ethnographers to plan their field work in a detailed manner. In terms of what to observe in the field, researchers are advised to pay attention to people (and other actors); to observe how they talk, behave, interact, move and talk. Also physical environment and the use of material artefacts should be recorded. Advice is also given on reporting one's own reactions, emotions and thoughts concerning the fieldwork.

What comes to documenting observation data, researchers are advised to write their observations down as soon as possible (depending on the situation this might be in situ, immediately afterwards, or at the end of the day). According to Emerson et al. (1995) field notes include both description portraying the physical environment, people and their 
actions, and dialogue representing the interaction. According to guidebooks, both should be documented as exact and detailed as possible, aiming to capture the language and expressions of the people in the field instead of researcher's own concepts and understandings. In terms of drawing conclusions based on the observations, some suggest that explicit analysis should be avoided during the fieldwork, while others argue that acts of observing and writing field notes are analysis per se. Despite this dissent, it is common to recommend that the researcher writes a separate personal diary of the researcher's experiences, thoughts and reflections to account how these might influence the fieldwork and interpretations it produces.

Informed by the guidelines, we started doing fieldwork with the women owner-managers of four small software service companies located in different parts of Finland. In our field work, the three of us researchers (and authors of this chapter) 'shadowed' (Bruni et al. 2004a) the owner-managers in their daily work. We followed each of them step by step observing their work and made notes of what happened. The first company of our fieldwork, Firemot Ltd. operates in a fast extending area of software business offering specialized services to large software companies. The second field work company, Kollabs helps other companies to automate their business processes through machine-to-machine communication. The third field work company, TRICT Ltd., is an ICT-training centre, which specializes in the development and use of ICT applications, system management, and data security. The fourth field work company, Content Ltd., is a tiny cross media and e-business company involved in customizing various types of software solutions for its customers.

In the first three companies, we made observations in the company offices (although occasionally we did also follow the owner-managers running their errands elsewhere). The fourth observation week was different because we followed the owner-manager travelling to work. We used, however, the same methods of making field notes at all four sites: we observed the owner-managers and their employees in their work, attended the meetings they had with partners, customers, and job applicants, manually recorded our field notes with pens and notebooks, switched between observing the same events together and taking turns in observation, assumed the role of non-participant observers by keeping quiet and stationary (when possible), adapted our observer roles according to the situation and context when our presence aroused curiosity and questions, participated actively when it seemed necessary (e.g. having meals together, carrying office shelves), and had both formal and informal discussions with various people about who we were and what we were doing. At the end of each day we (the researchers) shared and discussed our experiences with each other.

\section{Doing field work with Tiina}

\subsection{Focus of analysis}

In our analysis of the field work, we focus on the field notes written by Elina and Susan during one week's period of travelling and participating in the life and business operations of Tiina, the owner-manager of Content Ltd. The parts of the text marked with cursive are exact quotations from our field notes. To provide anonymity, the names of all people and companies are pseudonyms. 
This is what Elina wrote in her field notes in the beginning of the week:

'We spend this week observing the work of Tiina, an owner-manager of a small software service company Content Ltd. The office is located in Central Finland, but as Tiina had allocated this week for business trip, we decide to travel with her in one of the eastern counties of Finland. After all, we want to observe her work as an owner-manager of small business, whatever that work might be. Since we are travelling, we spend our time together around the clock. We stay in a house that we rented together, have our meals together, and spend our free time together.'

During the week, Elina and Susan observed how Tiina tracked down the use of electronic business among local care sector entrepreneurs, which was an assignment commissioned to her company by regional administration. We chose these particular field notes for the analysis because of their ability to illustrate selection and sense-making activities and textual practices that represent actors and encounters in the field. The analysis that follows emphasises one particular aspect of our ethnographic fieldwork, the construction of field notes, and focuses on two questions: what and who do we decide as relevant and worth writing down in the first place, and how we textually represent (or fail to represent) these research subjects and objects.

Tiina's company offers expert services in and around electronic business. To us, she characterized her path to entrepreneurship as 'traditional': graduating from a commercial institute, building a career in banking, getting married and staying home with kids, after which having further education in polytechnic. However, as Tiina describes, 'All the time the idea of entrepreneurship and independency haunted me, always cropping up in different situations'. Therefore, when Tiina was asked to participate in establishing a local business centre, she felt it was time to set up her own company in the process as well.

Tiina tells us that at first her work consisted of information technology training. Later on, she employed a few people and the company started to design home pages, portals and internet solutions for small and middle-sized companies, as well as consult them in cross media issues. Soon she realized that the company couldn't develop on its own, and decided to look for business partners. After some critical incidents, Tiina chose to concentrate on expert work instead of managing the business. Travelling is now an essential part of her work: 'I' $m$ where the customers are: consulting, training, networking and negotiating all around Finland.' According to her, 'We are a business of less than ten employees, but if you think about our close networks - the amount of people we actively buy from and co-operate weekly, with whom we have the same customers - we are no small business anymore.'

The reason for this ongoing business trip is an assignment commissioned to Tiina's company by regional administration: her job is to track down the use of electronic business in local small and medium sized companies. Therefore, Tiina (and us, the observing researchers) meet plenty of local entrepreneurs during the week. Most of them operate in the care sector, which is Tiina's first focus of the assignment. Tiina labels her role as 'the gray eminence, bridge builder or an agent' whose subtle overall plan is to link different actors doing developmental work in this field, 'spin a net', to create business for her own company through web services targeted at care entrepreneurs.

\subsection{Selective sense-making (the What's and Who's)}

The first remark we made when the three of us started to read and discuss our field notes collectively was that, in contrast to the earlier field notes from the first three software service 
companies, we had been even more selective in our observations and, particularly, in what we wrote down during the week with Tiina. In the first three field work companies, we took part in all meetings that we possibly could and were allowed to attend. This meant that we observed, among others, internal company meetings, informal lunch or coffee appointments, meetings with business partners, sales encounters, and recruitment interviews. In these situations we did our best to capture every conversation with every business partner in our notes, in detail.

A major difference in our fieldwork with Tiina was that, this time, we were not doing observations in the company premises within office hours. Elina commented in her notes that 'Fieldwork is hard work, and in the previous fieldwork companies I often waited the days to end to go home and rest. Here the time doesn't really matter, because the only free time is sleep time.' Another difference was that the people we met with Tiina were not, as in the previous companies, other ICT-sector entrepreneurs, managers, or experts. The business people that we met with Tiina were care sector entrepreneurs whose small-scale, grass-roots entrepreneurial ventures and caring world views seemed very different from the technobusiness orientations and behaviours that we had observed in the first three companies of our field work. Elina describes her first impression as 'Here it feels that we are really 'in the field'. It's a hands-on feeling compared to sterile techno-offices.'

When shadowing Tiina, we managed to follow the ideal of writing down as much as possible in a detailed manner, but only occasionally. What was striking to notice after wards was that we had excluded large parts of the interaction between Tiina and the care sector entrepreneurs. The fact that we had left considerable amount of this interaction unreported was justified by us in our field notes by appealing to the lack of time to write everything down, or by explaining that the care entrepreneurs were beyond the focus of our study. Their businesses seemed to have very little to do with techno-business issues as we understood them.

When we met Pirkko, a founder of a co-operative day care center, Susan wrote down a few facts about the center, but soon marked in her notes that 'I suppose Elina will write down this conversation, so I can concentrate on recasting what happened during this morning.' As time seemed to pass slowly, Susan began to describe the interior of the room. A telephone call for Pirkko interrupted her thoughts and when Tiina asked how much the members of the cooperative used information technology in their work, Susan momentarily concentrated again on listening the discussion between the parties involved. Soon, however, her thoughts wondered somewhere else, once again. Susan started to ponder 'Why is it that I am not writing down this conversation? Am I depreciating this conversation? In our previous fieldwork companies I wrote everything down word by word - but then again, it was so important, strategic discussion.'

Elina, in turn, listened to the discussion but did not report it in detail. Instead, she commented in her notes that 'This discussion is not 'technical'. It's more about practical issues such as communications, payment of wages, and daily activities. And the children play in the next room.' Later on she further noted that 'It might be quite interesting to analyse how these people interpret technology, and how they position themselves and others in care sector and their business. It feels, though, that is not relevant considering our focus. We're here to study Tiina and her business, not everyone else.' Similarly, in another meeting with two care entrepreneurs who had established a high quality home for the elderly Susan wrote: 'These women talk about intrinsic 
entrepreneurship. They are telling their story (it is a great story), but I am not going to write it down, because it's beyond the focus of our study.'

It is worth consideration why did we report Tiina's meetings with the care entrepreneurs rather superficially while in the previous three ICT-companies we had reported every conversation with every business partner in a detailed manner. With Tiina we justified our choices of not reporting these conversations by appealing to our research focus: we were studying Tiina and not 'anyone else' (as Elina writes), and because we did not have time to write everything down, we needed to focus on issues that were 'relevant'. But how come, in the other three field work companies, 'anyone else' seemed of interest (and 'relevant') and ended up on the pages of our notebooks, but not here? How come we characterized the previous discussions with various kinds of people as 'important' and 'strategic' business discussions, while we then neglected the conversations Tiina had with her potential business partners, the care entrepreneurs?

Although we had planned to follow the female owner-managers in all activities that they had during the observation week, and managed to do this in the first three companies of our field work, we did not manage to do this with Tiina. Why was it so? What happened? When we analyzed the situation afterwards, we came to the conclusion that we had strong pre-assumptions concerning what a proper technology intensive, ICT and software service business should be about, as well as which activities and partners would be central to this business and which ones would not be so central. When making observations and writing down field notes, we had categorized issues that we perceived closely related to technology business and ICTs as important, relevant and worth writing about. At the same time, we had categorized care work and care entrepreneurs as less relevant and non-important, even though they were Tiina's potential business partners. Where did our conceptions concerning 'what is important in business in general' and 'what is important in technology businesses in particular' come from, and how come we did not recognize them when being in the field?

At least part of the answer lies in our social identities as business school scholars. Within the business school context, we have developed an understanding of 'proper business' as something large-scale, strategic, or technological, which is far from the small scale microentrepreneurship represented by Tiina and the care entrepreneurs whom she met. Our preunderstanding coming from the business school context was not contradicted in the first three companies where we did fieldwork. Those companies were, in our minds, proper technology intensive business companies, and this is what we expected from the last company, too. When Tiina's company did not meet our expectations, we felt surprised, reluctant, and uncomfortable, but were unable to tackle these feelings and the reasons behind them while being in the field, only afterwards when reading and analyzing the field notes.

\subsection{Textual practices of representing the field (the How's)}

When we made the decision of not observing Tiinas' interaction with the care entrepreneurs, we constructed the care entrepreneurs as non-significant actors in contrast to the other actors that we connected more closely to the ICT-sector. This is not, however, the only problematic difference that we constructed in our field notes. Also Tiina, in the focus of our 
observation, gets her part of othering when evaluate her against the norms of business professionals. As a result, we characterized her behaviour as dubious in our field notes. In this process we as researchers become immersed in emotional contradictions that frame these characterizations, not being able neither to restrict the expression of emotions in a separate research diary, nor reflect in situ the powerful forces of frustration, irritation and guilt that we experienced in our fieldwork.

In the previous three fieldwork companies we followed the owner-managers and their daily work from a distance while our communication centred around work-related issues: we talked hardly nothing about our personal lives in the first three companies. For example, in our field notes we describe Jaana and Kaisa, owner-managers of two of the other software service companies we observed as follows: 'When communicating with us, Jaana is very straightforward and focused, and keeps her distance.' Or: 'Kaisa wants to define the level of our participation in her work. Basically, we are allowed to go everywhere in the office, but still she manages to keep her distance (...) She is the only person in this open plan office with her own (big!) room. If we want to talk to her, we have to knock on the door.' We respected their professional authority and personal distance even to the extent that we were hesitant (and a bit timid) to go and knock on their doors. Following this, they were able to adjust our presence - having a cigarette alone, closing office doors, going home at the end of the day - when they wanted (and so were we).

With Tiina, the situation was different. Since we were observing a business trip, we spent time together round-the-clock. Due to this closeness and Tiina's openness to share personal issues with us, the communication with her was very different from what we had experienced in the other field work companies. In a meeting with the entrepreneurs who had established a home for the elderly, Tiina takes an active role in the conversation by telling about her company and how she has managed to combine work and family life. She thanks her family for being so flexible, and keeps on telling about her children and the indispensable help she has received from her parents. Also in a meeting with Silja, one of the care entrepreneurs, the discussion turns to children when Silja weighs her chances as a single mother to participate in a seminar Tiina plans to arrange. Tiina shares stories about her four children, and appears empathetic towards Silja's childcare concerns. At some point the discussion turns to care work, and Silja mentions her mother's terminal care. Tiina starts immediately to share her own experiences of her parents-in-law, and the discussion revolves around very personal and sensitive topics. Susan comments in her field notes that 'I feel we should be invisible because they talk so personal matters'. Elina wonders later on 'how I should relate to all this 'private' stuff as a researcher'.

It is not only the topics of conversation that we feel confused about, but also Tiina's excessive talkativeness, towards which we express frustration in our field notes. In a situation where we wait for Silja in the old premises of a local association building, Elina writes: 'Tiina loves to talk, and tells one thing after another. The speech bounces from entrepreneurship and management to kid's illnesses and reverse sides of marriage. It's a flood of words that is hard to listen.' Later on, when Silja has already arrived and the discussion is well underway, Elina continues to comment: 'She definitely likes talking. It is such an informationflow that I struggle with what I can and find reasonable to catch in these notes'. During the week this information flow starts to irritate us more and more, and there are several remarks in both of our field notes about how Tiina speaks continuously about her personal matters, 
even to total strangers, and how confusing it is for us to keep up with the different spheres of her life (family, work, entrepreneurship). We do not know whether we are ascribed the role of researchers, friends, or confidantes, and where all this leads us in terms of our research.

As a result, we started to get feelings of guilt. After becoming very irritated by Tiina's behavior, Elina writes in her notes 'I feel I'm not able to listen to her anymore, but still I have to appear as interested. I'm not sure if this is a very fruitful attitude from me, but what can I do.' Susan, as well, questions the practice of field work in her notes: 'It's like social pornography: we intrude in someone's life and use it as research material. What worries me most is my own attitude towards Tiina. We analyse her life almost as if we would know better.' Elina continues to discuss the same topic in her post-field reflection notes: 'I'm struck by a bad conscience. I have wanted access in her life, and she has granted me this access, even though I'm a total stranger. Then I can't handle the situation and as a result, start to criticize her in my mind (and notes). Afterwards, it doesn't feel right. If she has been open enough to let me in her life, how can I, as a researcher, judge her?'

It is obvious that we recognize the problematic nature of fieldwork ethics, but fail to reflect in-situ why Tiina's behaviour caused such contradictory feelings for us. Down et al. (2006) note that interpersonal dynamics in the field can generate uncomfortable emotions. They also argue that these emotions inevitably influence the collection and interpretation of data, even though they hardly ever make their way to the published research report. In our case, these 'emotional dissonances' (Down et al. 2006) made us face the fact that, what we were frustrated and irritated about, was not so much Tiina herself or her behaviour (after all, we also talk much and share personal issues with those close to us), but our own pre-assumptions of how a business professional should or could behave in 'public' encounters.

The three other owner-managers we had observed earlier had enacted distance, focus and authority, i.e. qualities that are in line with the cultural image of a heroic business person, who is a tough, self-reliant, and combative man who works long hours, prioritizes business results over family and human relationships, controls his emotions, and never shows weaknesses (Binns 2008, 601, see also Bruni et al. 2004b). Accordingly, the dominant business discourse, strengthened and reproduced by media, educational practices and research, attributes business and work to the public domain of life; and home, family and kids to the private life (Ahl 2002). What Tiina did, however, was that she thoroughly mixed up the (assumedly separate) spheres of business and family, as well as rationality and emotions. Thus, her behaviour challenged the norm of business as serious work, which is performed as separate from home and family. She also confronted the assumption of business professionalism as enacting rationality, authority and distance. These social situations where our pre-assumptions about business professionalism were challenged caused us strong reactions of frustration and irritation. This also illustrates how our preunderstanding about business professionalism had directed us to textually represent Tiina in marginalizing ways compared to the female owner-managers of the other three companies, which had a better match with our expectations.

The narrow conception of business professionalism we had came up also in our notes regarding the care sector entrepreneurs and their expertise. An episode in which Susan describes the business activities of 'two middle-aged women' who run a home for the elderly is 
illustrative. Firstly, she notes that 'These women are truly professional entrepreneurs.' Later she continues to comment 'I'm once again impressed by the professional skills of these women.' Highlighting the professional skills of these women and making visible the unexpected nature of such observations reveals an underlying assumption about the unprofessional nature of their field of business, the care work. This becomes especially obvious in relation to information technology, utilization of which is one of the main topics in the meeting Tiina has arranged with these entrepreneurs.

According to our field notes we were also surprised of content of the conversation about information technology. That is, we did not expect the middle-aged female care entrepreneurs to be able to discuss technological issues on a professional basis with an expert. Subtly, but still strikingly, we reproduced the cultural hypothesis according to which technology, associated with expertise and skill, is more professional than care work, assumed to embody the 'feminine calling' (Henttonen et al., forthcoming).

\section{Discussion}

In ethnographic fieldwork we observe, make and give sense, and document social reality. Our field notes are textual representations of the observations and interpretations we have made, and as such, they are illustrative examples of the ways in which shared cultural understandings and our more local pre-assumptions have a bearing on what knowledge we produce and how. Our field descriptions of Tiina's work give evidence on what kind of issues we as business school researchers, and as researchers who had been in the 'same' (or so we thought) field before, found significant and worth writing and not writing down in our field notes. Our field notes illustrate what kind of meanings we attached to women owner-managers, business professionals and different fields of business (technology business and care business).

Recently, various types of constructionist and cultural approaches have become popular in small business studies (e.g. Bruni, Gherardi \& Poggio 2004a, 2004b, Down 2006). Being familiar with and also inspired by this literature, we considered ourselves open to various perspectives on women's small businesses when we started our research project and entered the field. Against this background it was interesting to notice that, despite our best intentions, we reproduced strong hierarchical relationships between the more professional and the less professional business activities and behaviours. In these processes of othering, a marginalized group became constructed against a norm, i.e. the care sector entrepreneurs became compared against the norm of more 'serious' businesses represented by technology intensive ICT-companies, which we considered that the first three companies of our field work represented well enough. At the same time, we compared Tiina's business activities and behaviours against our pre-assumptions concerning 'proper' business professionals, and pondered on the boundaries between public and private activities (an illustration of which is also the guilt we felt for expressing our emotions in the context of observation).

These processes of othering, illustrated in the previous sections of our paper, are closely related to the construction of gender in our research. The activities and meanings that became marginalized in our field notes, i.e. care, private, and emotionality, are those that are culturally associated with the feminine; while the valued standard norms of business, i.e. strategic orientation, rationality and authority, are attached to masculinity (Bruni et al. 
2004b, Eriksson, Henttonen \& Meriläinen 2008). Accordingly, women (and men) in feminized fields such as care are often marginalized in terms of professional status, authority and reward (Daiski \& Richards 2007), further reproducing the public-private divide and the dominant business professionalism discourse.

When analysing our field notes, it becomes evident how our social identities and the respective language and concepts that we use, the theories we draw from, and the academic practices we engage in construct (and enable) our understanding of the world. Furthermore, our research process was also shaped by our taken-for granted use of theoretical concepts and definitions, and the descriptions that we make about the subjects and events that we study. The purpose of reflexivity, then, is to unpack this in the way that the social and power relations of research are configured (Walby 2007, 1010). By practicing 'reflexivity of discomfort' (Pillow 2003), that is continuously questioning of the research process and the representations it produces, the processes of othering and marginalization become visible and accountable. This accountability refers to recognizing that the knowledge we produce is actively constructed by particular decisions and actions taken -- ones that we should take responsibility for (Rhodes 2009).

\section{Conclusion}

In this chapter we have explored the in situ construction and interpretation of the researchers' own ethnographic field notes. We have suggested that field notes can be illustrative examples of the ways in which social identities of the researchers and respective understandings and pre-assumptions have a bearing on what knowledge is produced and how. In particular, we have focused on the implications of two practices in constructing our own field notes: the selection and sense-making activities, and the textual practices of representation. Our study has shown that as the members of social groups such as business school researchers, we carry out fieldwork relying on the viable and acceptable ways of thinking, feeling, and doing in the contexts in which we operate.

Most importantly, however, we have illustrated how our earlier experiences from the field also produced more local and contextual pre-assumptions, which guided our expectations about what should happen when we continue with our field work. We have also illustrated how pre-assumptions leading social inclusion and exclusion with rather negative implications easily become reproduced on a continuous basis when we observe, take notes on, describe and analyse our research subjects - unless we practice reflexivity. Finally, because of the on-going nature of sense making and interpretation, we argue that ethnographers would benefit of practicing reflexivity throughout their research process, not only at certain points of it.

\section{References}

Ahl, H. (2002). The Making of the Female Entrepreneur. A Discourse Analysis of Research Texts on Women's Entrepreneurship. JIBS Dissertation Series No. 015, Jönköping.

Alvesson, M. \& Sköldberg, K. (2000). Reflexive Methodology: New Vistas for Qualitative Research. Sage, London.

Ashmore, M. (1989). The Reflexive Thesis. Writing Sociology of Scientific Knowledge. Chicago: The University of Chicago Press. 
Atkinson, P., Coffey, A., Delamont, S., Lofland, John \& Lofland, Lyn (2001). (eds.) Handbook of Ethnography. London: Sage.

Barter-Godfrey, S. \& Taket (2009) Othering, marginalisation and pathways to exclusion in health. In: Taket, A., Crisp, B., Nevill, A., Lamaro, G. Graham, M. \& Barter-Godfrey, S. (eds), Theorising social exclusion, pp. 166-172. Abingdon: Routledge.

Binns, J. (2008). The Ethics of Relational Leading: Gender Matters. Gender, Work and Organization, 15 (6), 600-620.

Bruni, A. \& Gherardi, S. \& Poggio, B. (2004a). Doing Gender, Doing Entrepreneurship: An Ethnographic Account of Intertwined Practices. Gender, Work and Organization, Vol. 11, No. 4, 406-429.

Bruni, A. \& Gherardi, S. \& Poggio, B. (2004b). Entrepreneur-mentality, gender and the study of women entrepreneurs. Journal of Organizational Change Management, 17 (3), 256-268.

Clifford, J. \& Marcus, G. (Eds.) (1986). Writing culture: The poetics and politics of ethnography. Berkeley, CA: University of California Press.

Coffey, A. (1999). The Ethnographic Self. Fieldwork and the Representation of Identity. London: Sage.

Daiski, I. \& Richards, E. (2007). Professional on the Sidelines: the Working Lives of Bedside Nurses and Elementary Core French Teachers. Gender, Work and Organization, 14 (3), 210-231.

Davies, C. (2008). Reflexive Ethnography. London: Routledge.

Down, S. (2006). Narratives of Enterprise: Crafting Entrepreneurial Self-Identity in a Small Firm. Cheltenham UK: Edward Elgar.

Down, S., Garrety, K. \& Badham, R. (2006). Fear and Loathing in the Field: Emotional Dissonance and Identity Work in Ethnographic Research. M@n@gement, 9 (3), 86107.

Emerson R., Fretz R. \& Shaw L. (1995). Writing Ethnographic Fieldnotes. Chicago: University of Chicago Press.

Ellemers, N., Spears, R. \& Doosje, B. (1999). Social identity: Context, content and commitment. Oxford: Blackwell.

Eriksson, P. \& Henttonen, E. \& Meriläinen, S. (2008a). Managerial work and gender Ethnography of cooperative relationships in small software companies. Scandinavian Journal of Management, Vol. 24, No. 4, 354-363.

Eriksson, P. \& Henttonen, E. \& Meriläinen, S. (2008b). Growth Strategies of Women Controlled SMEs: A Case Study of Finnish Software Companies, International Journal of Business Excellence, Vol. 1, No 4: 434-447.

Eriksson, P., Hearn, J., Henttonen, E., Hiillos M., Jyrkinen M., Katila S., Meriläinen S., Moisander, J., Niemi, H., Rolin, K., Tallberg, T. \& Vanhala, S. (eds.) (2005). Gender and Organizations in Flux? Hanken, Helsinki. Swedish School of Economics and Business Administration, Department of Management and Organisation, Management and Organisation. Research Reports 60.

Eriksson, P. \& Kovalainen, A. (2008). Qualitative Methods in Business Research. Los Angeles, London, New Delhi \& Singapore: Sage.

Etherington, K. (2006). Becoming a Reflexive Researcher. London and Philadelphia, Jessica Kingsley Publishers. 
Hardy, C. \& Phillips, N. \& Clegg, S. (2001). Reflexivity in organization and management theory: A study of the production of the research 'subject'. Human Relations. Vol. 54(5), 531-560.

Haslam, A. (2001). Psychology in Organizations - The Social Identity Approach. London, Sage Publications.

Henttonen, E. (2010). An Ethnographic Study on Women's Small ICT Businesses in Finland. Acta Universitatis Oeconomicae Helsingiensis, Series No A-371.

Henttonen, E., LaPointe, K., Pesonen, S. \& Vanhala, S. (forthcoming). A Stain on the White Uniform - Discursive Construction of Nurses' Industrial Action in the Media.

Hogg, M., Terry, D., \& White, K. (1995). A Tale of Two Theories: A Critical Comparison of Identity Theory with Social Identity Theory. Social Psychology Quarterly, 58, 255269.

Lynch, M. (2000). Against Reflexivity as an Academic Virtue and Source of Priviledged Knowledge. Theory, Culture \& Society. Vol. 17(3): 26-54.

Maton, K. (2003). Reflexivity, Relationism \& Research: Pierre Bordieu and the Epistemic Conditions of Social Scientific Knowledge. Space \& Culture, 6 (1), 52-65.

Pillow, W. (2003). Confession, catharsis, or cure? Rethinking the uses of reflexivity as methodological power in qualitative research. International Journal of Qualitative Studies in Education, 16 (2), 174-196.

Rhodes, C. (2009). After Reflexivity: Ethics, Freedom and the Writing of Organization Studies. Essai. Organization Studies, 30 (6), 653-672.

Rosaldo, R. (1993). Culture \& Truth: The Remaking of Social Analysis. Boston: Beacon.

Van Maanen, J. (1988). Tales of the Field: On Writing Ethnography. Chicago: University of Chicago Press.

Walby, K. (2007). On the Social Relations of Research: A Critical Assessment of Institutional Ethnography. Qualitative Inquiry, 13 (7), 1008-1030.

Woolgar, S. (1988). Reflexivity is the Ethnographer of the Text. In: Woolgar, S. (ed.) Knowledge and Reflexivity: New Frontiers in the Sociology of Knowledge. London, Sage, 14-34.

Wolcott, H. (1999). Ethnography: A Way of Seeing. Walnut Creek, CA: AltaMira Press. 


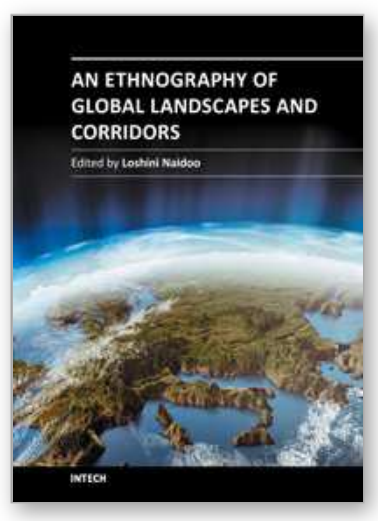

\author{
An Ethnography of Global Landscapes and Corridors \\ Edited by Dr. Loshini Naidoo
}

ISBN 978-953-51-0254-0

Hard cover, 270 pages

Publisher InTech

Published online 09, March, 2012

Published in print edition March, 2012

The chapters presented in this book draw on ethnography as a methodology in a variety of disciplines, including education, management, design, marketing, ecology and scientific contexts, illustrating the value of a qualitative approach to research design. The chapters discuss the use of traditional ethnographic methods, such as immersion, observation and interview, as well as innovative ethnographical methods which have been influenced by the new digital culture. The latter challenges notions of identity, field and traditional culture such that people are able to represent themselves in the research process rather than be represented. New approaches to ethnography also examine the use and implication of images in representation as well as critically examining the role and impact of the researcher in the process.

\title{
How to reference
}

In order to correctly reference this scholarly work, feel free to copy and paste the following:

Päivi Eriksson, Elina Henttonen and Susan Meriläinen (2012). Ethnographic Field Notes and Reflexivity, An Ethnography of Global Landscapes and Corridors, Dr. Loshini Naidoo (Ed.), ISBN: 978-953-51-0254-0, InTech, Available from: http://www.intechopen.com/books/an-ethnography-of-global-landscapes-andcorridors/ethnographic-field-notes-and-reflexivity-

\section{INTECH}

open science | open minds

\section{InTech Europe}

University Campus STeP Ri

Slavka Krautzeka 83/A

51000 Rijeka, Croatia

Phone: +385 (51) 770447

Fax: +385 (51) 686166

www.intechopen.com

\section{InTech China}

Unit 405, Office Block, Hotel Equatorial Shanghai

No.65, Yan An Road (West), Shanghai, 200040, China

中国上海市延安西路65号上海国际贵都大饭店办公楼 405 单元

Phone: +86-21-62489820

Fax: +86-21-62489821 
(C) 2012 The Author(s). Licensee IntechOpen. This is an open access article distributed under the terms of the Creative Commons Attribution 3.0 License, which permits unrestricted use, distribution, and reproduction in any medium, provided the original work is properly cited. 